\title{
Zirconium Phosphonate/1,4,5,8-Naphthalenediimides Self-Assembled Films
}

\author{
MAGALI A. RODRIGUES ${ }^{1}$, DENISE F.S. PETRI, ${ }^{1}$, \\ MARIO J. POLITI ${ }^{2}$ and SERGIO BROCHSZTAIN ${ }^{2}$ \\ Laboratório Interdepartamental de Cinética Rápida, \\ ${ }^{1}$ Departamento de Química Fundamental and ${ }^{2}$ Departamento de Bioquímica, \\ Instituto de Química, Universidade de São Paulo, \\ Cx. Postal, 26077 - 05513-970 São Paulo, SP, Brazil.
}

Manuscript received on September 8, 1999; accepted for publication on September 15, 1999; presented by JosÉ M. RIVERos

\begin{abstract}
The formation and characterization of self-assembled films of zirconium phosphonate / N,N'-di(2phosphonoethyl)-1,4,5,8-naphthalenediimide (DPN) is presented. The films were produced on glass substrates by deposition of alternating layers of $\mathrm{Zr}^{+4}$ and DPN. Films containing up to 16 layers on each side of the substrate were obtained and monitored by absorption spectroscopy and ellipsometry. When irradiated, the initially colorless films turned to a persistent pinky color reminiscent of that of DPN anion radical. These films are a promising material to the development of photovoltaic devices.
\end{abstract}

Key words: zirconium phosphonates, naphthalenediimides, self-assembled films.

\section{INTRODUCTION}

Naphthalenediimides are a group of compounds that have become increasingly important in the past few years, due to their use in a series of applications, ranging from the biomedical area to the science of materials (Green \& Fox 1995, Barros et al. 1997, Kheifets et al. 1977, Saito et al. 1990). Chemical or electrochemical reduction of $1,4,5,8$ naphthalenediimides gives rise to a stable anion radical, making them very attractive for the construction of conducting materials (Miller et al. 1993) and for artificial photosynthesis (Greenfield et al. 1996). For most applications a fine control of the spatial organization of the system is required. Thus the incorporation of aromatic-diimides in a number of macromolecular systems has been investigated (Jazwinski

Correspondence to:

Mario J. Politi, mjpoliti@usp.br

Sergio Brochsztain, sbrochs@quim.iq.usp.br et al. 1987, Hamilton et al. 1998, Brochsztain \& Politi 1999).

A way to achieve a fine level of control over the properties of the system is to assemble the molecules in thin films. Here it is reported the preparation and characterization of self-assembled thin films of N,N'-di(2-phosphonoethyl)-1,4,5,8naphthalenediimide (DPN) /zirconium phosphonate (Lee et al. 1988a, Lee et al. 1988b).

\section{MATERIAL AND METHODS}

The films were assembled on glass substrates (BK7) and on silicon wafers by depositing alternating layers of DPN (Chae et al. 1998, Rodrigues et al. 1999) and $\mathrm{Zr}^{+4}$ (Scheme 1). The substrates were previously treated by known procedure (Katz et al. 1991). The treatment resulted in a surface rich in phosphonate groups, which adsorbed a layer of $\mathrm{Zr}^{+4}$ when exposed to an aqueous solution of $\mathrm{ZrOCl}_{2}$. 
The zirconated surface is then exposed to an aqueous solution of DPN. Multilayers are obtained by sequential treatment with $\mathrm{ZrOCl}_{2}$ and DPN solutions.

\section{SCHEME 1}
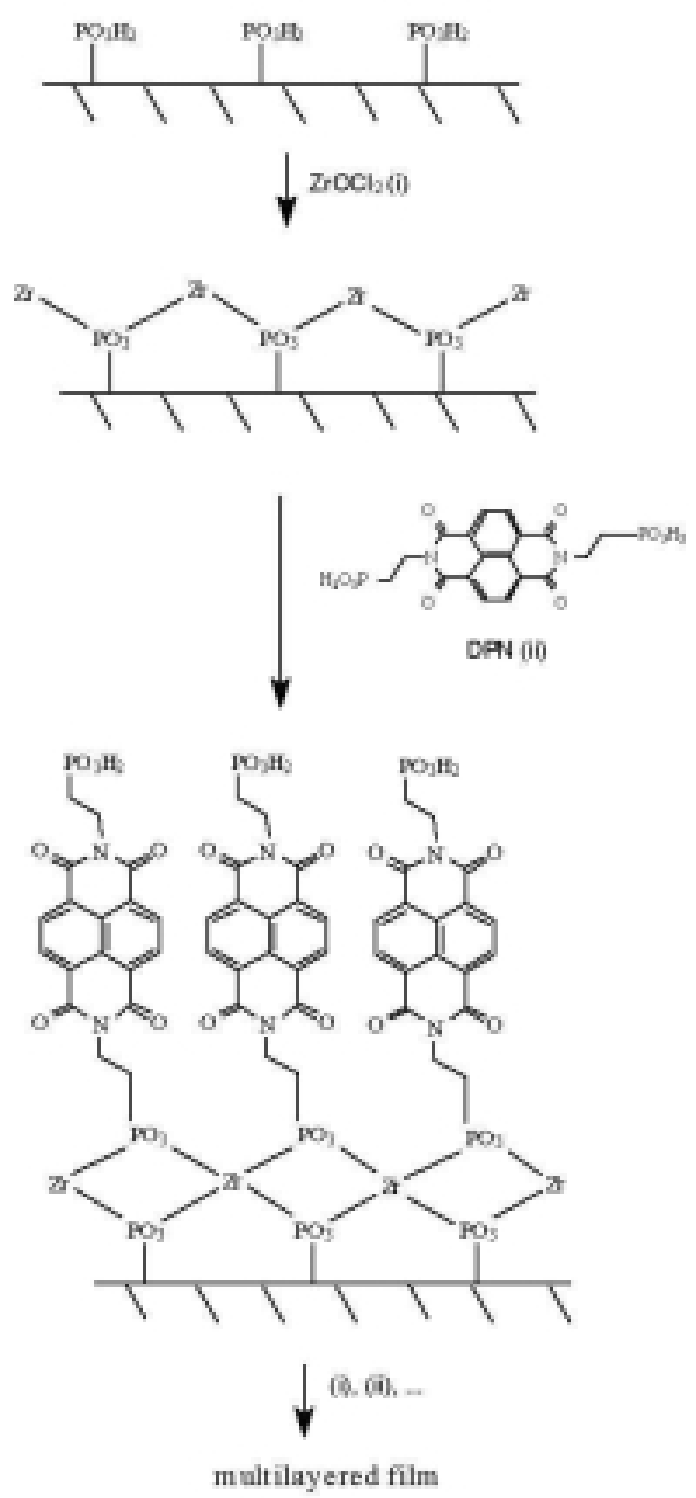

RESULTS AND DISCUSSION

Film formation was followed by electronic spectroscopy and by ellipsometry. A plot of the absorbance at $360 \mathrm{~nm}$ versus the number of DPN layers deposited was linear up to 16 layers (Fig. 1A). In parallel a plot of the ellipsometric thickness versus the deposition number was linear having a thickness of $10.2 \AA$ per layer (Fig. 1B).
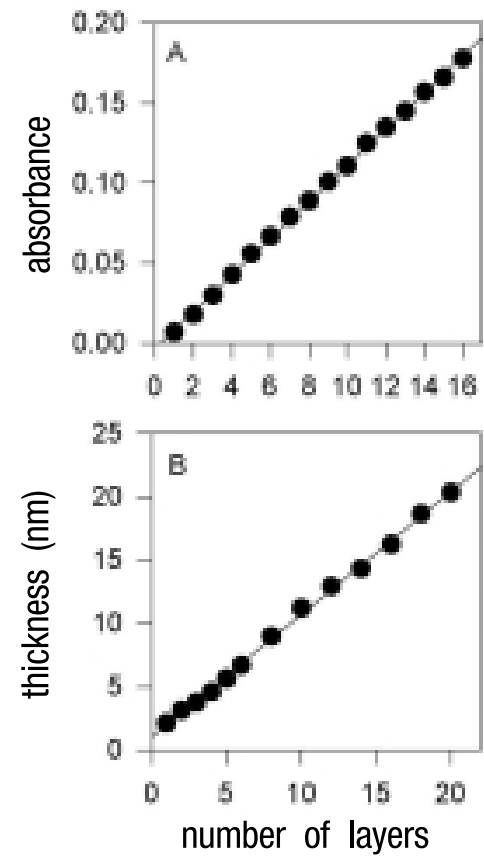

Fig. 1 - (A) Absorbance of a DPN film (at $360 \mathrm{~nm}$ ) as a function of the number of deposited layers on both sides of a glass substrate. (B) Ellipsometric thickness of a DPN film as a function of the number of layers deposited on one side of a silicon wafer.

The absorption spectra of films with different thickness are shown in Fig. 2. The spectra of DPN in water and acetonitrile solutions are also shown for comparison. The spectrum in water is typical of monomeric 1,4,5,8-naphthalenediimides (Barros et al. 1997, Brochsztain \& Politi 1999), showing welldefined vibrational structure. In acetonitrile, on the other hand, loss in the vibrational structure is seen which is attributed to aggregated DPN (Brochsztain $\&$ Politi 1999). The spectra of the film show the same trends observed in the acetonitrile spectrum, suggesting that the diimide rings are stacked in the films.

The emission spectrum of a DPN film is shown in Fig. 2B. The red-shifted, unstructured, excimerlike emission band observed for the film is in sharp contrast to the emission of DPN in water solution. 


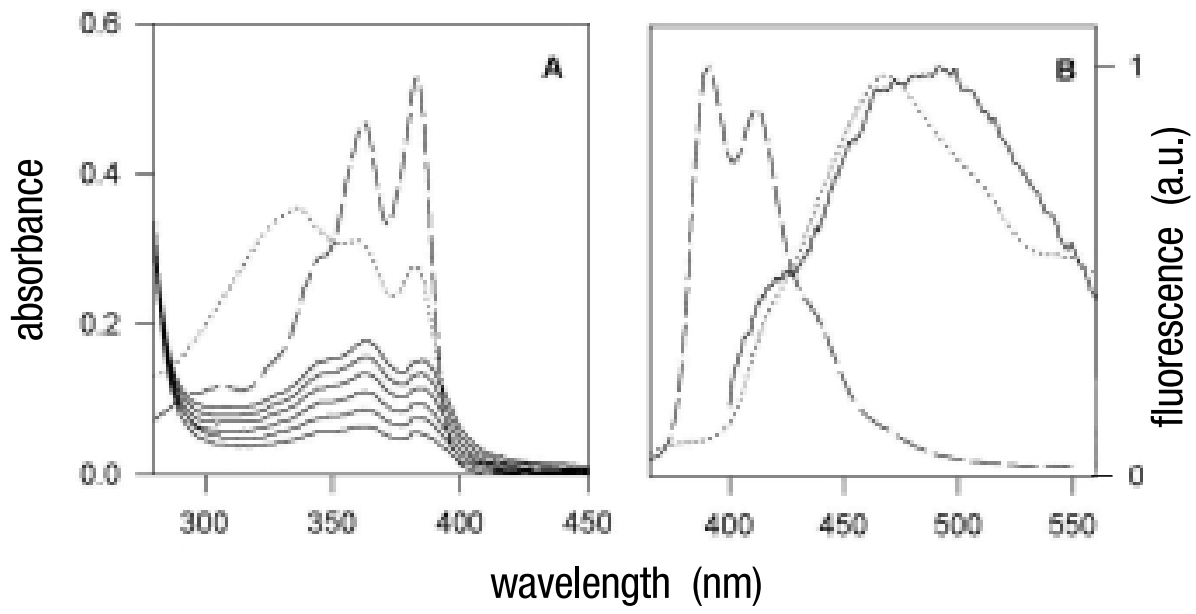

Fig. 2 - (A) Absorption spectra of DPN films with 6, 8, 10, 12, 14 and 16 layers on each side of a glass slide (-) and of DPN ([4 $\left.\left.\times 10^{-6} \mathrm{M}\right]\right)$ solutions $\left(5 \mathrm{~cm}\right.$ path length) in $\mathrm{CH}_{3} \mathrm{CN}(\cdots)$ and water (- - ). (B) Emission spectra of a DPN film with 16 layers on each side of a glass slide (-) and of DPN $\left(\left[5 \times 10^{-6} \mathrm{M}\right]\right)$ solution in water $(---)$. The emission spectrum of a suspension of microcrystalline N,N'-dibutyl-1,4,5,8-naphthalenediimide in water is also shown $(\cdots)$. Spectra are normalized to $\mathrm{I}_{\max }=1$, and $\lambda_{\mathrm{ex}}=310 \mathrm{~nm}$ in all cases.

The emission spectrum of the film was very similar to that of a suspension of microcrystalline N,Ndibutyl-1,4,5,8- naphthalenediimide in water (Barros et al. 1997) (Fig. 2B). In either case the spectra can be attributed to emission from stacked chromophoric units in the solids, a typical case of a selftrapped exciton (Rashba 1987). Thus, both absorption and emission measurements point to a stacked arrangement of the aromatic rings within the films.

The DPN/zirconium phosphonate films photoactivity was observed when a 16-layer film (on each side of a glass slide) was irradiated under steady state or flash photolysis conditions. Thus, irradiation of the films with a $\mathrm{Hg}$ lamp (20 h) resulted in persistent spectroscopic changes, with the decrease of the diimide absorption band and the appearance of a tail extending to longer wavelengths. When the films were photolyzed with a pulsed Nd:YAG laser $(355 \mathrm{~nm})$, a long-lived bleaching of the DPN absorption band was observed, together with the appearance of a transient absorption at longer wavelengths. Both signals did not decay within the time scale of the experiment (up to $100 \mu s$ ). In these ex- periments, the appearance of a slightly pink color on the slide could be observed. We are presently investigating the nature of this photochemical process and in particular the possibility that stable imide radicals were formed. In conclusion the self assemble of DPN on zirconated glass surfaces and the initial steps towards its characterization and utilization are presented.

\section{ACKNOWLEDGMENTS}

The support by grants from Brazilian agencies FAPESP, CNPq, Finep, and PADCT is gratefully acknowledged. M.A.R. is a doctorate fellow from CNPq. S.B. acknowledges FAPESP for a post-doctoral fellowship.

\section{REFERENCES}

Barros TC, Brochsztain S, Toscano VG, Berci FP \& PoLITI MJ 1997. Photophysical characterization of a 1,4,5,8-naphthalenediimide derivative. J Photochem Photobiol A: Chem 111: 97-104.

Brochsztain S \& Politi MJ 1999. Solubilization of 
1,4,5,8-Naphthalenediimides and 1,8-Naphthalimides through the Formation of Novel Host-Guest Complexes with $\alpha$-cyclodextrin. Langmuir 15: 4486-4494.

Chae HJ, Lee MS, Kim YI \& Lee H 1998. Formation of Self-assembled Zirconium N,N '-bis(benzyl phosphonic acid) 3,4,9,10-Perylene(dicarboximide) Multilayer films on Silicon Substrate. Bull Korean Chem Soc 19: 27-29.

GREEN S \& Fox MA 1995. Intramolecular Photoinduced Electron-Transfer from Nitroxyl Radicals. J Phys Chem 99: 14752-14757.

Greenfield SR, Walter AS, Gosztola D \& WasielEWSKI MR 1996. Multistep Photochemical Charge Separation in Rod-like Molecules Based on Aromatic Imides and Diimides. J Am Chem Soc 118: 67676777.

Hamilton DG, Davies Je, Prodi L \& Sanders JKM 1998. Synthesis, Structure and Photophysics of Neutral $\pi$-associated [2]Catenanes. Chem-Eur J 4: 608620 .

Jazwinski JAJ, Blacker J, Lehn M, Cesario J, GuilHeM \& PASCARD C 1987. Cyclo- Bisintercalands: Synthesis and Structure of an Intercalative Inclusion Complex and Anion Binding Properties. Tetrahedron Lett 28: 6057-6060.

Katz HE, Scheller G, Putvinski TM, Schilling ML, WiLSON WL \& ChIDSEy CED 1991. Polar Orientation of Dyes, in Robust Multilayers by Zirconium Phosphate- Phosphonate Interlayers. Science 254: 1485-1486.
Kheifets GM, Martyushina NV, Mikhailova TA \& Khromov-Borisov NV 1977. Diimides of 1,4,5,8Naphthalenetetracarboxylic Acid: Molecular Complexes and Half-wave Potentials of Polarographic Reduction. J Org Chem USSR 13: 1159-1164.

Lee H, Kepley JL, Hung-Gi Hong \& Mallouk TE 1988a. Inorganic Analogs of Langmuir-Blodgett Films: Adsorption of Ordered Zirconium 1,10-Decanebisphosphonate Multilayers Films on Silicon Surfaces. J Am Chem Soc 110: 618-620.

Lee H, Kepley LJ, Hung-Gi Hong, Akhter S \& MalLOUK TE 1988b. Adorption of Ordered Zirconium Phosphonate Multilayer Films on Silicon and Gold Surfaces. J Phys Chem 92: 2597-2601.

Miller LL, Zhong CJ \& Kasai P 1993. Production of a Polymer with Highly Anisotropic Conductivity and Structure by Co-Electroprecipitation of an Imide Anion Radical and Polycation. J Am Chem Soc 115: 5982-5990.

RASHba EI 1987. Self-trapping of Excitons - Selected Chapters Rashba EI Sturge, MD Eds; Elsevier, Chapter 7, p 273-327.

Rodrigues MA, Brochsztain S, Barros TC, Baptista MS \& Politi JM 1999. pH-Dependent Excited-State Properties of N,N'-di(2-phosphonoethyl)-1,4,5,8naphtalenediimide. Photochem Photobiol 70: 3539.

Saito I, Takayama M \& Matsuura T 1990. Phthalimide Hydroperoxides es Efficient Photochemical Hydroxyl Radical Generators. A Novel DNA-Cleaving Agent. J Am Chem Soc 112: 883-884. 